\title{
Movimento Maker com Robótica de Baixo Custo: Um Estudo sobre o Ensino de Ciências no IFRS
}

\author{
Vanessa Faria de Souza ${ }^{1}$ \\ ${ }^{1}$ Instituto Federal de Educação, Ciência e Tecnologia do Rio Grande do Sul (IFRS) - \\ Campus Ibirubá \\ CEP 98.200-000 - Ibirubá - RS - Brazil \\ vanessa.souzadibiruba.ifrs.edu.br
}

\begin{abstract}
The Maker Movement is related to the proposal of learning based on autonomy (do-it-yourself) and creativity, and low-cost educational robotics has emerged as an accessible alternative that makes Movement Maker actions feasible. This uses scraps of old computer equipment, as well as the electronic prototyping platform of free hardware and single board as is the case with Arduino. In this context, this manuscript seeks to detail the research project developed in IFRS, which aimed to employ the foundations of the Maker Movement and its educational possibilities, in low-cost educational robotics workshops, promoting the construction of innovative solutions in the face of problematic situations that they will be instigated by generating themes such as sustainability, environmental resources, preservation, among others. In this way, it was intended to generate prototypes and products that can be applied as solutions to real problems.
\end{abstract}

Resumo. O Movimento Maker está relacionado com a proposta de aprendizado baseado na autonomia "faça você mesmo" e criatividade e a robótica educacional de baixo custo surgiu como uma alterativa acessível que viabiliza ações do Movimento Maker. Esta se utiliza de sucatas de equipamentos de informática antigos, assim como a plataforma de prototipagem eletrônica de hardware livre e de placa única, como é o caso do Arduíno. Neste contexto, este manuscrito busca detalhar o projeto de pesquisa desenvolvido no IFRS, que teve como intuito empregar os fundamentos do Movimento Maker e suas possibilidades educacionais, em oficinas de robótica educacional de baixo custo, promovendo a construção de soluções inovadoras ante a situações problemáticas que irão ser instigadas a partir de temas geradores como: sustentabilidade, recursos ambientais, preservação, dentre outros. Pretendeu-se, dessa forma, gerar protótipos e produtos que possam ser aplicados como soluções para problemáticas reais.

\section{Introdução}

O Movimento Maker está relacionado com a proposta de aprendizado baseado na autonomia "faça você mesmo" e na criatividade. Esse movimento explora o exercício da imaginação, o trabalho em equipe, a postura empreendedora e o desenvolvimento da capacidade de inovação, que são aspectos importantes na formação. Complementando essa informação, o uso de novas tecnologias é crescente em qualquer área, assim como dentro das instituições de ensino e a robótica educacional tem mostrado notáveis 
progressos em uma diversidade de ambientes. Apesar da utilidade e da versatilidade dessa ferramenta ela ainda não é utilizada em larga escala em nosso país, fato este que ocorre, principalmente devido ao alto custo dos equipamentos.

Diante desse problema, surgiu a robótica educacional de baixo custo, que se utiliza de sucatas de equipamentos de informática antigos, assim como da plataforma de prototipagem eletrônica de hardware livre, como é o caso do Arduíno. A robótica educacional, tem provado despertar interesse nos alunos, por permitir manuseio físico e participação ativa no processo de desenvolvimento de projetos, o que caracteriza a forma de aplicação metodológica do Movimento Maker.

É notória a falta de motivação entre os alunos do ensino fundamental e médio quanto as disciplinas na área de exatas, fato que assinala a principal problemática abordada nesse trabalho e devido a isso, os educadores sempre buscam ferramentas para incentivar os estudantes. Uma das ferramentas que tem se mostrado eficaz nesse sentido é a robótica educativa. Como mostra Silva (2010), o ensino de robótica desperta nos alunos o interesse pelo estudo de ciências, incluindo física, matemática e computação.

A participação em projetos de robótica educativa, no estudo desenvolvido pelo autor, acarretou a elevação na autoestima e autoconfiança dos alunos, levou a maior aproveitamento nas disciplinas curriculares e melhorou o relacionamento entre os colegas. Um dos limitadores do uso de robótica educativa, como já dito, é o alto custo dos equipamentos, o que impede a adoção na maioria das escolas públicas. No entanto, como prova Silva (2010) com a utilização de hardware livre e sucata de material de informática é possível produzir equipamentos a um custo até 20 vezes menor do que dos equipamentos comerciais. Cabe também salientar, com relação ao tema deste trabalho, que o Movimento Maker está vinculado a uma proposta de aprendizado baseado na autonomia (faça você mesmo) e com a popularização de recursos tecnológicos como: a impressora 3D, a máquina de corte a laser, as práticas de marcenaria, uso de sucatas e kits de robótica de baixo custo (como Arduino); houve a possibilidade da difusão deste movimento.

Segundo Samagaia (2015) o movimento conhecido como "Makers" se fundamenta em uma tradição frequentemente revisitada, trata-se do "faça você mesmo" ou "do it yourself" (DiY) que vem sendo desdobrado em um conceito complementar ao "do it with others" (DiWO). A essência das ações destes coletivos consiste na constituição de grupos de sujeitos, amadores e/ou profissionais atuando nas diferentes áreas ligadas a ciência e a tecnologia, que se organizam com o objetivo de suportar mutuamente o desenvolvimento dos projetos dos seus membros.

Desta forma, o Movimento Maker, junto com a Robótica Educacional de baixo custo podem oferecer uma valiosa contribuição ao processo de ensino e aprendizagem de Ciências. Esta combinação pode explorar o exercício da criatividade, o trabalho em equipe e o desenvolvimento da capacidade de inovação, que são aspectos considerados importantes no trabalho com as Ciências, e aprimorar os conhecimentos adquiridos pelos alunos. A Tecnologia tão presente na vida das crianças e adolescentes, deixou de ser apenas uma ferramenta e hoje influencia a cultura e o comportamento da sociedade e pode-se dizer que o Movimento Maker possibilita o surgimento de novas formas de ensinar e aprender.

Isto posto, pretendeu-se com esse projeto, além de desenvolver a pesquisa na área, por meio de publicações e elaboração de procedimentos educativos construídos 
com base na Robótica Educacional em conjunto com movimento Maker, também realizar experimentos e, portanto, sua aplicação também gera benefícios para comunidade de alunos com a qual o projeto foi desenvolvido.

A contribuição científica gerada por esse projeto foi a análise do impacto da prática da robótica educativa no interesse pelo estudo de ciências entre os alunos do ensino técnico integrado ao ensino médio, bem como o desenvolvimento de técnicas e procedimentos para sua realização utilizando-se do Movimento Maker como metodologia de aplicação.

A contribuição tecnológica foi a aquisição de conhecimento para o desenvolvimento de produtos robóticos de baixo custo, com utilização de hardware livre combinado com sucata de material de informática. O barateamento dos produtos permite que mais estudantes de escolas públicas tenham acesso aos equipamentos de robótica educativa. Ademais, pode-se citar o desenvolvimento de tecnologias para construção de kits de robótica educativa de baixo custo: os projetos desenvolvidos, com a utilização de hardware e software livre, devem ser disponibilizados para os alunos participantes.

No cenário proposto, este trabalho então empregou os fundamentos do Movimento Maker e suas possibilidades, em oficinas de robótica educacional de baixo custo, com o público alvo selecionado, promovendo a construção de soluções inovadoras no ensino de Ciências, utilizando uma abordagem de construção a partir de situações problemáticas, que foram instigadas a partir de temas geradores como: sustentabilidade, recursos ambientais, preservação, dentre outros. Pretendeu-se dessa forma gerar protótipos e produtos que possam ser aplicados como soluções para problemáticas reais.

\section{Movimento Maker}

A humanidade com o objetivo de aprimorar habilidades cognitivas, desenvolve tecnologias que podem estimular de forma criativa a aprendizagem. A abordagem construcionista [Papert, 1980], por exemplo, instiga habilidades e competências, por meio de atividades em que o aprendiz, realiza ações, em outras palavras "coloca a mão na massa" construindo algo de seu interesse e para o qual está motivado. Utilizando-se de diversos procedimentos, o protagonista desse processo, aprende a resolver problemas em aspectos distintos de sua vida.

Nesse sentido a cultura Maker, está associada com práticas presentes na Ciência da Computação, um indivíduo "Maker" combina tecnologia, conhecimento e computação e suas ações são motivadas para concretizar projetos específicos [Milne; Riecke; Antle, 2014]. Essa metodologia está relacionada à aprendizagem prática na qual o estudante é protagonista do processo de construção do seu conhecimento, aprendendo assuntos de seu interesse o que pode ocasionar uma maior motivação. $\mathrm{Na}$ aprendizagem prática ocorre a valorização da experiência do educando, permitindo que esse aprenda com seus erros e acertos, com a satisfação em compreender assuntos e temas do seu próprio interesse, que estão relacionados com seu cotidiano [Blikstein, 2013].

O aprendiz passa a atuar como autor do próprio ambiente de aprendizado, de forma descentralizada passa a produzir seu próprio material didático e ajuda os demais colegas na resolução dos problemas apresentados. Ideias que estão sendo relacionadas ao termo Pensamento Computacional que proporciona aprender de maneira criativa, no 
qual o modelo de troca de conhecimento entre mediador e estudante deixa de ser somente expositivo [Blikstein, 2013].

O termo Pensamento Computacional, se enquadra nesse projeto pela questão da robótica estar incluída como elemento impulsionador da inovação. Esse termo cunhado por Janette Wing em 2006, apresenta-se como: "uma maneira de resolver os problemas, conceber sistemas e compreender o comportamento humano que se baseia em conceitos fundamentais da Ciência da Computação”. As competências contidas nesse termo podem ser utilizadas para estimular a capacidade de resolução de problemas em qualquer área do conhecimento e em qualquer fase da vida, explorando a criatividade e a construção do saber.

Santana (2015) identifica o pensamento computacional como o desenvolvimento de habilidades que favorecem a resolução de problemas, em que, por meio da organização do modo de pensar, é possível expandir a capacidade mental, permitindo resolver os mais diversos níveis de desafios. A aprendizagem prática e o pensamento computacional convergem para um ensino que prioriza a criatividade, inventividade e produtividade dos alunos, que são protagonistas no desenvolvimento do seu próprio conhecimento.

\section{Robótica e Aprendizagem em Ciências}

De acordo com Vygotsky (1998) a aprendizagem é baseada principalmente no relacionamento das pessoas e é caracterizada pela mudança de comportamento, pois com ela há o desenvolvimento de habilidades. No caso do projeto proposto, essas habilidades são desenvolvidas a partir da interação com os protótipos robóticos, com a utilização dos princípios do Movimento Maker e com a mediação do professor/pesquisador.

Segundo o autor bielorrusso, nas tentativas do sujeito aprendiz para resolver problemas atinge-se a zona de desenvolvimento proximal, que é a distância entre o desenvolvimento real, aquele que cada pessoa é capaz de realizar por si mesma, e a zona de desenvolvimento potencial, aquele que a pessoa consegue fazer com ajuda de outros mais capazes. Essas interações estabelecem-se entre professor - aluno - robô e são bastante positivas para o desenvolvimento do domínio do simbolismo, trazendo vantagens sociais, cognitivas e afetivas.

A experimentação, muito utilizada nesta pesquisa, é uma prática na qual, segundo Borba (1999), problemas abertos são propostos pelo mediador (professor) e ocorre uma exploração em grupo de temas relacionados com a Ciências. A ideia central da experimentação é trabalhar conceitos modelando fenômenos. Nada mais entusiasmaste que o professor lançar um desafio em que os alunos se vejam como os coautores de seu aprendizado e possam manipular os objetos e formas reais na obtenção das respostas para o que foi proposto resolver.

Nesse sentido, a robótica é uma ferramenta significativa para esse tipo de atividade. Partindo de um estímulo, "problema" de cunho real, que o professor, orientador (mediador) propõe, como "desenvolver certo movimento para o robô". Logo, o aluno se põe a pensar para resolver tal atividade do robô e se vê motivado a buscar novas relações nas Ciências e no mundo e vice-versa. Então se dá a busca por conceitos a partir desse estímulo real, no qual o aluno vai compor seus próprios conceitos e identificar uma ciência própria, extinguindo o que Freire (1987) chama de 
conhecimento bancário, que é o que ocorre quando o aluno é visto pelo professor como uma conta na qual este vai depositando a sua contribuição em forma de conhecimento.

Ele próprio, "o aluno", constrói uma ponte até o conhecimento e, depois de encontrar o necessário para a ação, volta ao estágio inicial, agora com a pergunta respondida e a possibilidade de aplicar os conceitos vistos. Essa forma de pensar o processo de ensino desbanca também a necessidade de acompanhar o livro didático à risca, como relata Echeverría (2008), os professores, no geral, não tiveram esse preparo para organizar tanto as atividades como a forma de avaliar, pois na maioria das vezes se limitam a acompanhar o livro-texto. Há também a questão da não abstração, o aluno não é obrigado a ter que abstrair a Matemática para um contexto real, por partir de uma necessidade real. Ele busca os conhecimentos matemáticos essenciais para a resolução de uma tarefa específica e de seu interesse, o que se salienta ter um papel motivador.

O professor, por sua vez, vai direcionando o aluno pelo caminho matemático e não mais dosando os conteúdos e fórmulas que o aluno deve saber. Gera-se assim um ciclo no qual o aluno é quem vai em busca do conhecimento pela necessidade criada em um contexto real, e ao encontrar as respostas para suas perguntas, dentro do campo lógico-matemático, volta ao real para aplicar o seu conhecimento, agora lapidado e construído por si com auxílio do professor. Cada etapa permite que o aluno, juntamente com o professor, compreendam concretamente o que é a construção da aprendizagem. Tanto professor como aluno criam uma relação afetiva com o projeto, comprometendose com a tarefa proposta e conciliando as novas aprendizagens com habilidades requeridas. Equilibrando habilidades e desafios, eles experimentam um alto grau de motivação e satisfação, e o que se aprende fazendo fica muito mais enraizado na mente [Papert, 1980].

Para a construção da autonomia, segundo Freire (2002), não basta dar liberdade, é preciso pensar nas formas pelas quais trabalha-se com os conteúdos que se ensina em sala de aula. Quanto mais criticamente se exerça a capacidade de aprender, tanto mais se constrói e desenvolve curiosidade epistemológica, sem a qual não se alcança o conhecimento cabal do objeto. Papert (1980) diz que um indivíduo pode aprender, e a maneira com que aprende depende dos modelos que tem disponível. Isso levanta, de forma recursiva, a questão de como se aprende nesses modelos. Assim, as leis de aprendizagem devem versar sobre como estruturas intelectuais crescem para fora uma da outra e sobre como, no processo, elas adquirem forma lógica e emocional.

Por exemplo: considere o desafio lançado pelo professor para a construção de uma montanha-russa, modelo de brinquedo muito comum em parques de diversão, portanto objeto de conhecimento dos alunos. Ao manipularem as peças ou objetos do kit robótico, partem do pensamento abstrato para o concreto, pois deve haver a concepção de quais mecanismos serão adequados para a construção que viabilizará os movimentos esperados. Esse ato de "brincar" do real para o imaginário cria no educando a possibilidade de exercitar o domínio do simbolismo [Vigotsky, 1998]. Contextualizando a construção com o objetivo específico do professor, fica estabelecida uma conexão dos conhecimentos prévios com os novos a que se propõe.

Durante o processo de construção, há uma constante interação do pensamento abstrato com o concreto. Esse processo de construção de protótipos proporciona um ambiente de aprendizagem muito dinâmico para o processo de mediação a ser realizado pelo professor, que constantemente intercederá com novos conhecimentos tecnológicos 
e instigará novos desafios. São comuns os conflitos, nos quais o professor negociará e ouvirá diferentes ideias e opiniões dos alunos para os mesmos problemas propostos e orientará quanto ao uso racional e efetivo da tecnologia. Trabalhos assim estimulam os alunos a aprender e conhecer coisas. Há estreitamento com o tema, e os conhecimentos prévios equilibram-se com novas habilidades e desafios. Os alunos pensam sobre como as coisas funcionam, experimentam, observam, analisam e corrigem os possíveis erros.

Ao terminarem a construção do protótipo, podem ser analisados muitos conceitos na prática, como princípios da Física - a transformação da energia potencial em energia cinética, além dos conceitos de atrito, aceleração - e da Matemática medições, medidas de ângulos, o estudo das equações de segundo grau; ou seja, uma infinidade de temas e conteúdos podem ser inseridos, trabalhando com robótica no ensino-aprendizagem de ciências.

\section{Metodologia}

Este projeto se desenvolveu por meio de pesquisa-ação, na qual os pesquisadores e participantes estão envolvidos de modo cooperativo e participativo (SOMEKH, 2003). Dessa forma, além de desenvolverem técnicas e procedimentos para o ensino de Ciências por meio da Robótica Educacional, houve a validação dos mesmos por meio da aplicação. O presente trabalho foi executado em etapas, por isso uma divisão em 4 fases distintas foi uma opção didática para sua implementação. Essas fases são apresentadas na Tabela 01 .

Tabela 1. Fases do Desenvolvimento

\begin{tabular}{|c|c|c|}
\hline ID & FASE & ATIVIDADES \\
\hline \multirow[b]{2}{*}{1} & \multirow[b]{2}{*}{ Instalação } & Montagem de um Ambiente propício a aplicação dos conceitos propostos. \\
\hline & & $\begin{array}{l}\text { Análise do Contexto de Ensino Aprendizagem de Ciências em Colégios } \\
\text { Estaduais. }\end{array}$ \\
\hline \multirow{6}{*}{2} & \multirow{6}{*}{ Planejamento } & $\begin{array}{l}\text { Levantamento das possibilidades de aplicação de robótica educativa } \\
\text { utilizando os princípios do Movimento Maker (tipos de equipamentos já } \\
\text { disponíveis). }\end{array}$ \\
\hline & & $\begin{array}{l}\text { Desenvolvimento de uma revisão sistemática de literatura para seleção dos } \\
\text { principais trabalhos realizados na área. }\end{array}$ \\
\hline & & Seleção dos conteúdos que serão abordados. \\
\hline & & $\begin{array}{l}\text { Elaboração das técnicas e procedimentos com base nos conteúdos e } \\
\text { também na Robótica educacional, utilizando a prática do Movimento } \\
\text { Maker. }\end{array}$ \\
\hline & & Seleção do público de aplicação. \\
\hline & & Elaboração do plano de ação. \\
\hline \multirow[t]{2}{*}{3} & \multirow[t]{2}{*}{ Execução } & $\begin{array}{l}\text { Desenvolvimento de projetos de robôs (com "faça você mesmo"): os } \\
\text { projetos serão implementados incluindo o ciclo de vida completo, desde o } \\
\text { planejamento, distribuição dos papéis, monitoramento, correção de falhas } \\
\text { durante o processo, testes e análise 'postmortem'. }\end{array}$ \\
\hline & & Realização das Oficinas. \\
\hline 4 & Encerramento & $\begin{array}{l}\text { Sistematização das lições aprendidas e divulgação dos resultados, inclusive } \\
\text { por meio de exposição pública, e em especial pela publicação dos } \\
\text { resultados alcançados. }\end{array}$ \\
\hline
\end{tabular}

\section{Fonte: Autora}

Desta forma, os participantes do projeto tiveram que se envolver nesse ambiente para conseguir estruturar de forma satisfatória um projeto que obtivesse resultados positivos para tanto foi necessário: 
1. Estudar sobre Arduino, aprender a Programar e sobre o funcionamento do seu hardware. Assim como entender técnicas e tecnologias de robótica educacional e de baixo custo;

2. Montar modelos de exemplo, como braços robóticos e pequenos robôs de diversas funções para serem modelos para o demais;

3. Organizar no Laboratório os Kits que configuram o laboratório Maker;

4. Verificar o pleno funcionamento do Ambiente, e manter a organização;

5. Pesquisar problemáticas que podem ser utilizadas como temas geradores para serem aplicados nas oficinas;

6. Organizar as oficinas com base nos temas geradores;

7. Organizar e ajudar a ministrar as oficinas, e dar apoio na construção das soluções pensadas pelos participantes;

8. Ao fim de cada oficina, realizar a aplicação de alguns testes e pesquisas de satisfação com os participantes, dessa forma foi possível verificar a satisfação dos alunos, e realizar a catalogação dos protótipos e ou produtos montados, para comporem o rol dos resultados alcançados;

9. Por fim, sistematizar os dados em forma de relatórios técnicos para posterior divulgação.

\section{Considerações Finais}

Este movimento inicial para implantação de um ambiente institucional para o desenvolvimento de um FABLAB (Laboratório de Fabricação para os alunos) no campus Ibirubá do IFRS foi enriquecedor e proporcionou uma evolução na maneira como se ensina no curso Técnico em Informática Integrado ao Ensino Médio, em resumo salienta-se como fortes indicativos de que este método pode ser um grande auxiliar no desenvolvimento educacional os seguintes pontos:

1. O envolvimento dos alunos na aprendizagem utilizando da metodologia do Movimento Maker foi grande e melhorou sua autoestima, assim como sua forma em se empenhar nos estudos;

2. Melhorou a aprendizagem graças a motivação experienciada pelo projeto.

3. Foi possível vivenciar o incentivo institucional para a implementação do movimento Maker em outras disciplinas além da proposta pelo projeto, o que melhorou o ambiente de trabalho; e

4. Por fim, a satisfação dos alunos em poderem experenciar a construção do seu conhecimento.

Quanto a área técnica os principais resultados identificados foram: Os Protótipos implementados com Arduino e o Movimento inicial para implantação de um ambiente institucional para o desenvolvimento de um FABLAB. Além disso, o projeto foi exitoso, e auxiliou na compreensão do processo de ensino aprendizagem e também a entender como a construção do conhecimento é importante e mostrou uma nova forma de ensino que pode ser ampliada nos Institutos Federais. Uma última vantagem identificada foi a utilização do Arduíno no qual se tem à disposição uma plataforma de 
hardware já modelada, e reconfigurável via firmware dispensando em muitos casos os conhecimentos em eletrônica digital e arquitetura de microcontroladores em relação ao controlador da placa, bastando conhecimento em algoritmos para fazer uma aplicação. De forma geral, houve um grande amadurecimento no decorrer do da execução do projeto.

\section{Agradecimentos}

O presente trabalho foi realizado com apoio do Instituto Federal de Educação, Ciência e Tecnologia do Rio Grande do Sul (IFRS).

\section{Referências}

Blikstein, P. Digital fabrication and 'making'in education: The democratization of invention. FabLabs: Of machines, makers and inventors", 2013.

Borba, M. C. Calculadoras gráficas no Brasil. In: FAINGUELERNT, E. K., Gottlieb, F. C. (Org.) Calculadoras gráficas e educação matemática. 2.ed. Rio de Janeiro: Art Bureau, 1999.

Echeverría, A. R. et al. Formação de grupos interdisciplinares de professores numa interação universidade -escola. XIV Encontro Nacional de Ensino de Química (XIV Eneq). 2008.

Freire, P. Pedagogia da autonomia: saberes necessários à prática educativa. São Paulo: Paz e Terra, 2002.

Milne, A.; Riecke, B.; Antle, A. Exploring Maker Practice: Common Attitudes, Habits and Skills from Vancouver's Maker Community. Studies, v. 19, n. 21, p. 23, 2014.

Papert, S. Mindstorms: Children, computers and powerful ideas. Basic Books, inc. Artes Médicas: Porto Alegre, 1980.

Somekh, D. Theory and passion in action research. Educational Action Research, Oxf Action Research ord., v. 11, n. 2, p. 247-264, 2003.

Silva, A. F. da. RoboEduc: uma metodologia de aprendizado com robótica educacional. Natal, Tese (doutorado) - Programa de Pós-Graduação da Universidade Federal do Rio Grande do Norte, 2010.

Vygotsky, L. S. A formação social da mente. São Paulo: Martins Fontes, 1998.

Wing, J. M. Computational Thinking. Communications of the AACM, v. 49, n. 3, p.33$35,2006$. 